\title{
Luis de Gusmão contra a hybris teórica
}

\author{
Luis de Gusmão against the theoretical hybris
}

GUSMÃO, Luis de. O fetichismo do conceito: limites do conhecimento teórico na investigação social. Rio de Janeiro: Topbooks, 2012, 258 p.

\section{Sérgio da Mata}

sdmata@ichs.ufop.br

Professor adjunto

Universidade Federal de Ouro Preto

Rua do Seminário, s/n - Centro

35420-000 - Mariana - MG

Brasil

Palavras-chave

Ciências sociais; História; Explicação histórica.

Keywords

Social sciences; History; Historical explanation. 
Esse bagulho (Stoff) 'bateu' [...]. Nos anos sessenta o número de dependentes aumentou assustadoramente. De início, o bagulho circulou em pequenos grupos, depois passou a ser comercializado em grandes quantidades, principalmente nas universidades. Era tomado por via extravenosa - através de puro trabalho conceitual, através de exercícios de leitura. Os efeitos não traziam qualquer risco. A droga se chamava teoria (RAULFF; SCHLACK 2012, p. 4, grifos nossos).

Assim abriu a prestigiosa Revista para História das Ideias um de seus últimos editoriais. O mundo dá voltas, e como: num ensaio originalmente publicado em 1972, Reinhart Koselleck (1977) se levantava contra a "indigência teórica" dos estudos históricos. Já hoje, multiplicam-se os sinais, aqui e ali, de cansaço ante a hybris teórica. Não diria tanto que se trata de uma hipocondria teórica, semelhante à hipocondria epistemológica diagnosticada por Clifford Geertz algumas décadas atrás. Mas talvez chegue perto. Mesmo no campo dos estudos literários aumenta número daqueles que abdicam das ilusões do teoricismo (PATAI; CORRAL 2005).

Um historiador estrangeiro, em recente visita a nosso país, perguntava: "Por que todos aqui parecem tão preocupados com teoria?". Numa revista como esta, que se tornou o principal fórum de reflexão sobre a história da historiografia e a teoria da história em nosso país, a discussão sobre os limites da teoria não tem como ser evitada. Seria dar as costas aos "sinais dos tempos".

O livro do sociólogo Luis de Gusmão presta-se, como nenhum outro disponível em nosso mercado editorial, a esta tarefa - tanto mais porque ele é também a expressão mais visível de uma nova atitude das ciências sociais em relação à ciência histórica. Atitude pautada por uma vontade sincera de diálogo; algo que, seja dito, não existia até bem pouco tempo. Estamos inclinados a ver em $O$ fetichismo do conceito um caso exemplar daquele gênero que, em outras plagas, foi batizado de antissociologia. Gusmão se encontra numa situação similar à de autores como Helmut Schelsky e Friedrich Tenbruck, os mais conhecidos antissociólogos produzidos pela tradição sociológica alemã. Trata-se de um gênero kamikase, onde a desmistificação das pretensões desmedidas da própria disciplina confunde-se com a crítica dos intelectuais, e no qual a afinidade em relação ao pensamento histórico é inegável. Até onde pude perceber, participando de um ou outro debate, conversando com um ou outro colega, a reação ao livro de Gusmão entre os sociólogos brasileiros foi de uma discreta simpatia, mais que de rejeição.

Isso valerá também para os historiadores? Quando da publicação da primeira edição - que se esgotou rapidamente - deu-se uma acalorada discussão a seu respeito nas "redes sociais". Como sempre, entre nós, as polêmicas em torno de uma obra são mais intensas quando ninguém teve ainda ensejo de ler o livro. Esta resenha é resultado de minha tentativa de submeter as críticas de Gusmão, duras muitas delas, a um escrutínio mais cuidadoso e sereno.

Primeira constatação: a sociologia de Gusmão não padece deste pecado típico da juventude, a arrogância (e isso talvez descreva com relativa precisão a atitude das disciplinas mais novas ante as mais velhas). Desde princípios do século passado, passou-se a acreditar que esta vetusta senhora, a história, 
nada tinha a ensinar às nascentes ciências sociais. Não: ela, a história, é quem deveria aprender com as novas ciências do homem. Praesens tempus magister vitae et historiae... Mas em Gusmão, felizmente, não se vê nada disso.

Alguma confusão pode ser suscitada pelo título escolhido por Gusmão. O fetichismo da teoria certamente seria mais adequado. De toda forma, tudo está dito no subtítulo, e para o qual o leitor deverá estar atento: Limites do conhecimento teórico na investigação social. O que Gusmão nos propõe é colocar em questão as ilusões do "teoricismo". Em certo sentido, ele escreve o livro que Thompson verdadeiramente deveria ter escrito em seu A miséria da teoria. Depois de tomar de assalto as ciências sociais pelo menos desde meados do século passado, o teoricismo adquiriu, gradativamente, o estatuto de atitude intelectual dominante. Diante disso, trata-se, acredita Gusmão, de reabilitar a importância das "investigações sociais conteudísticas" (GUSMÃO 2012, p. 127137). $\mathrm{E}$, inclusive, de defender o emprego da "terminologia vulgar" ante as pretensões do "jargão técnico" (GUSMÃo 2012, p. 50).

Antes de ceder à tentação de desqualificar tais críticas recorrendo a este termo inapelável (posto que vago, e quanto mais vago mais inapelável), o de "positivismo", proponho ao leitor acompanhar os argumentos e a exposição de Gusmão. O teoricismo estaria caracterizado, por exemplo, na "apresentação quase ritual de credenciais teóricas" (GUSMÃO 2012, p. 21). Ninguém há de negar que a carteirada teórica é o pão nosso de cada dia nas humanidades hoje. Basta pensar ainda no famoso "capítulo teórico" de nossas dissertações 262 e teses universitárias (o autor desta resenha receia ter de admitir que não foi capaz fugir à regra). O automatismo em torno das "premissas teóricas" levou-nos a um ponto tal em que não mais se sabe onde termina o esforço analítico e onde começa a mera observância das rígidas regras de composição do texto acadêmico; onde termina a teoria e onde começa a retórica. As analogias estruturais entre teoria e retórica, de resto, há muito foram postas às claras por Hans Blumenberg. A retórica, como a teoria, é tudo o que resta "aquém da evidência". Sendo o efeito retórico a alternativa "à evidência que não se pode, ou ainda não se pode obter, pelo menos aqui e agora" (BLUMENBERG 2001, p. 411412), fica claro por quê o "capítulo teórico", via de regra, é posto na abertura dos trabalhos acadêmicos. Cumpre-se uma obrigação e, então, finalmente se pode passar ao que interessa. Se o leitor e o próprio autor do trabalho ainda se lembram das premissas teóricas assumidas lá no início, já é outra história.

Gusmão entende que faríamos melhor em deixar de lado a parafernália dos modelos e o jargão teoricista, pois "a leitura mais atenta, mais exaustiva dos grandes teóricos sociais [...] não transforma, como num passe de mágica, pessoas intelectualmente acanhadas em indivíduos de espírito" (GUSMÃo 2012, p. 45). Significa assim colocar em campo, subrepticiamente, uma noção tornada politicamente incorreta hoje em dia, mas que o nosso cotidiano não se cansa de evocar e confirmar: a de talento. Talento, esse imponderável da vida, é sem dúvida mais decisivo que a teoria.

O elogio que Gusmão faz da obra historiográfica de Tocqueville (GUSMÃO 2012, p. 93-94) expressa a sua rebelião contra as ilusões holísticas de autores 
como Marx, Bourdieu, Luhmann e tantos outros. O que propriamente atua ali são as "classes", os "campos" ou os "sistemas", enquanto que os indivíduos não passam de peões no grande tabuleiro das teorias sociais de longo alcance. Ao usuário de tais esquemas teóricos resta uma única e pequena satisfação: a de encaixar as peças no tabuleiro - algo que Arnold Gehlen ironizava com a expressão Erfüllungsglück. A reabilitação ora em curso de estratégias individualizantes de pesquisa, inclusive no campo da sociologia qualitativa e da história das ideias, é atestada pelo recente livro de Dieter Heinrich (2011) sobre a lógica e a história dos grandes insights filosóficos. É precisamente nesse espírito que Gusmão fala no "risco de negligenciarmos o papel do indivíduo na vida social" (GUSMÃo 2012, p. 156). Tendo sido, desde sempre, a ciência do individual, do singular, é apenas natural que para ele a história se torne um interlocutor privilegiado na crítica ao teoricismo e às ilusões holísticas.

Que qualidades fazem o grande historiador, ou o grande estudioso da conditio humana? Para Gusmão bastaria um forte senso de honestidade intelectual e acuidade de visão para que as ciências sociais e a história fossem capazes de levar adiante sua tarefa de interpretar/explicar a realidade. É como se tudo se resumisse a uma questão de vocação, por um lado, e de bom senso, por outro (talvez devesse ainda acrescentar: de amor à verdade). Bastaria, numa palavra, recorrer ao que Gusmão chama de "senso comum".

Mas o que vem a ser tal coisa? Gusmão não enfrenta a questão. Ele apenas nos mostra como grandes escritores (Stendhal, Flaubert, Eça de Queirós etc.) foram perfeitamente capazes de descrever e dar explicações adequadas para uma infinidade de questões unicamente à base do "senso comum" (GUSMÃO 2012, p. 100). Ao mesmo tempo, porém, Gusmão critica duramente todo aquele que desrespeita o imperativo da neutralidade axiológica. Censura Leon Tolstoi por seu tom "moralista e doutrinário", por "confundir sermão e realidade" (GUSMÃO 2012, p. 40); enquanto que Georg Simmel mais Ihe parece um "filósofo moral travestido de sociólogo" (GUSMÃo 2012, p. 147).

Tal juízo está longe de fazer justiça a Simmel. Fará também justiça a Tolstoi? Coloca-se, antes, a questão: a literatura não estabelece ou se baseia amplamente em juízos de valor ${ }^{1}$ Ademais, há algo de demasiado ligeiro na ideia de que as obras daqueles grandes romancistas expressaria o "senso comum". Diria que Gusmão se torna vítima do efeito bumerangue do próprio argumento. $\mathrm{O}$ fato de que se possa fetichizar conceitos não significa que devamos abrir mão do conceito tout court. O uso pouco elucidativo que faz da noção de "senso comum" é prova disso. Veja-se, por exemplo, sua crítica - que em larga medida partilhamos - à fetichização das generalizações nas ciências do homem. Gusmão defende, sadiamente, que não estabeleçamos "uma ruptura epistemológica com o universo intelectual do homem comum" (GUSMÃO 2012, p. 54). Todavia, a realização de um trabalho sistemático de investigação por vezes exige que façamos exatamente isso: que não tomemos por expressão

\footnotetext{
${ }^{1}$ O Settembrini de $A$ montanha mágica não estava tão longe assim de Tolstoi quando perguntava: "A arte é moral na medida em que desperta. Mas o que sucede quando ela faz o contrário?". A tentativa de depuração moral da literatura me parece ainda menos factível que a da historiografia.
} 
de verdade expressões do senso comum tais como "todo político rouba", "o povo brasileiro é simpático" etc. Para retomar o pensamento de um autor que Gusmão dá mostras de apreciar, Alfred Schütz, pode-se dizer que a partir do instante em que eu reflito sobre o alcançe, motivações e consequências de minhas ações, não mais me situo no âmbito do "senso comum". Eu me desloco para uma outra região da consciência que não aquela voltada para a paramount reality do mundo da vida (onde tudo é aceito como não-problemático porque sempre-foi-e-há-de-ser-assim). Adoto assim uma postura reflexiva, em suma: teórica (SCHÜTZ 1973, p. 207-259). Trata-se, aqui, mais de atitude teórica que de "teoria". Theoria em seu sentido primevo: capacidade de ver e tornar visível aquilo que, no automatismo das rotinas, fora naturalizado e, precisamente por isso, tornado "invisível". Theoria como sinônimo de reflexividade. A contrapelo, se necessário for, da "teoria". Como expressão, e para dizê-lo de forma concisa, de uma atitude de vigília: "reflexão permanente", dizia Schelsky.

Ora, salvo engano, os "literatos de gênio" (GUSMÃO 2012, p. 43) que Gusmão nos propõe tomar como exemplo raramente expressam ou reproduzem o "senso comum". Do contrário dificilmente seriam literatos de gênio. ${ }^{2}$ Por outro lado, não deixa de ser legítimo que a nós outros, seres humanos medianos, vez por outra seja facultado o direito ao eventual uso das muletas conceituais, dos modelos, dos tipos ideais. O recurso pouco esclarecedor ao termo "senso comum" em $O$ fetichismo do conceito não deixa de soar como uma advertência nesse sentido.

264 Nas duas primeiras partes do seu livro, Gusmão volta suas baterias contra o teoricismo, como já foi dito. Na última parte, intitulada "Notas epistemológicas sobre Sérgio Buarque de Holanda historiador" (GUSMÃO 2012, p. 172-336), ele aplica as premissas ali desenvolvidas à análise de uma obra clássica de nossa historiografia. $O$ argumento central pode ser resumido em bem poucas palavras: à medida em que se afasta de seu livro de estreia e amadurece como historiador, Sérgio Buarque torna-se cada vez menos suscetível à tentação do teoricismo. Seu famoso artigo de 1974 sobre Ranke tende a confirmar esta leitura. O gradativo esvaecimento do "sociologismo" (o termo é de Gusmão) em suas obras caminha par e passo com uma redescoberta, mesmo revalorização, do historicismo.

Gusmão percorre Raízes do Brasil, Monções, Visão do paraíso e Do Império à República à caça daqueles momentos em que o historiador deixa trair um "sociologismo confuso" (GUSMÃO 2012, p. 201) ou que evidenciariam recaídas no "dedutivismo" (GUSMÃO 2012, p. 258). Sua crítica à metafísica buarquiana do ethos do aventureiro (GUSMÃO 2012, p. 242) são convincentes e ecoam aquelas feitas por Jessé Souza (2000). É certo que, ao se colocar esta tarefa, Gusmão não estava obrigado a se familiarizar - visto que sua intenção é de natureza estritamente epistemológica - com uma vasta literatura produzida

\footnotetext{
${ }^{2}$ Não evitarei esta palavra, sobre a qual a última palavra ainda não foi dita. Embora Gadamer tenha escrito que o século XIX assistira a "apoteose" do gênio, Thomas Carlyle já acreditava presenciar o seu ocaso (se subjaz uma deliciosa ironia a esse desacordo entre duas mentes brilhantes, que não se a impute a mim). Ver a história do conceito de "gênio" em Joachim Ritter (1974).
} 
nas últimas décadas sobre o mestre paulista. Por esta razão, o pesquisador interessado em aprofundar-se no estudo dos livros de Sérgio Buarque extrairá relativamente pouco das análises de Gusmão.

De toda sorte, não é pouco o que Gusmão poderia ter ganho caso tivesse prestado maior atenção às muitas investigações "conteudísticas" que a respeito têm sido publicadas. Várias delas têm, inclusive, relativizado cada vez mais a hipótese do weberianismo latente de Raízes do Brasil. Onde Gusmão crê identificar um excesso de ascendência do sociólogo alemão em Monções (GUSMÃO 2012, p. 262-263), poder-se-ia igualmente apostar (convém ser cuidadoso) numa ascendência spengleriana. A passagem de Monções em que se explora a conexão entre o uso de canoas e racionalização do habitus sertanejo só aparentemente se baseiam em Weber. Há aqui, provavelmente, muito maior influxo do estilo de pensamento característico de $O$ declínio do Ocidente. Este não é o lugar para discutir a importância que teve o grande nome da filosofia vitalista do entre-guerras sobre Sérgio Buarque. O que cabe ressaltar é antes o fato de que, neste ponto, a abertura do sociólogo Gusmão face à historiografia não chega às últimas consequências. Se no início de $O$ fetichismo do conceito a história surge um exemplo a ser seguido, ao fim ela se torna objeto de dissecação, sem que, para isso, a própria história tenha sido chamada a contribuir. Fosse este o caso, Gusmão teria evitado formulações como a da página 272, em que lamenta a "adesão incondicional" de Sérgio Buarque "à tese weberiana". Na verdade, Buarque aproximou-se relativamente cedo de um dos primeiros grandes críticos da chamada tese weberiana: Henri Hauser, de quem foi assistente na Universidade do Distrito Federal.

A excessiva acribia com que Gusmão localiza e critica longamente (GUSMÃO 2012, p. 310-314) um suposto "paramarxismo" em Buarque - pelo simples fato de fazer uso, inclusive com as devidas ressalvas, do conceito de "classes médias" em Do Império à República - é no mínimo desproporcional. Desproporcional face à acuidade e liberdade de pensamento ali expressas. Desproporcional, se pensarmos no emprego infinitamente mais rígido e mecânico que, àquela época, se costumava fazer dos conceitos marxistas. Desproporcional, enfim e sobretudo, porque, como reconhece Gusmão, são bem "raras" (GUSMÃO 2012, p. 319) as evidências de "paramarxismo" em Sérgio Buarque! Se os riscos do paramarxismo para a história e para as ciências sociais são assim tão iminentes como acredita Gusmão, bastaria o exemplo do próprio Max Weber para matizar um pouco o furor antimarxista de O fetichismo do conceito. De Weber, Gusmão parece ter assimilado como poucos o postulado da neutralidade axiológica; entretanto Weber estava longe de demonstrar a mesma rejeição pelo materialismo histórico. O estudo cuidadoso das primeiras grandes publicações acadêmicas de Weber mostra a que ponto ali se lança mão, de forma criativa e nada subserviente, de inúmeros conceitos marxistas (MATA 2013). Mais: se de fato há um "projeto normativo" em Raízes do Brasil, não se pode dizer que um estudo clássico como $A$ ética protestante e o espírito do capitalismo estivesse inteiramente livre do que Gusmão rejeita sob a expressão "preocupações normativas tutelares" (GUSMÃO 2012, p. 282). Tais preocupações, a começar por Comte e Durkheim, nunca estivarem inteiramente ausentes das ciências sociais. 
A despeito das discordâncias expressas acima, que balanço se pode fazer após a leitura de $O$ fetichismo do conceito?

Para mim, seria mais ou menos este: não há como pensar a teoria e os excessos em teoria sem um esforço de falar a partir de fora da teoria. E isso por meio de uma epoché radical. Atualmente estamos menos necessitados de uma "teoria crítica" que de uma crítica da teoria. Ao tematizar as vantagens e desvantagens da teoria para a vida, algo de que, como sublinhamos, cada vez mais pessoas se dão conta, o antissociólogo Luis de Gusmão vai ao ponto. A imprescindibilidade da teoria está posta em questão. Com a palavra, os partidários (verdadeira legião) do teoricismo.

Não concluo. Concluir soaria pretensioso. Melhor recorrer a outro mestre, um mestre do filosofar-em-histórias, e deleitar-se com esta sua pequena história crítica... da teoria.

Os atenienses não inventaram a filosofia, da qual pareciam estar orgulhosos. Em ambos os pólos do mundo grego, na costa jônica da Ásia Menor e no dórico sul da Itália, haviam nascido puras culturas da teoria. Demonstraram ser totalmente incompatíveis.

Aí radicava a oportunidade dos atenienses de se destacar, eliminando esta insuportável oposição: a que se dá entre a teoria genética da natureza, dos jônios, e a da lógica estática do Ser, de Eléia. Sem dúvida, tinha de ser irreconhecível que se tratava de um trabalho posterior sobre um resultado sem expectativas. Portanto, teve de inventar um protofilósofo ático próprio. Como ele não havia existido, pôde levar o nome mais sensato, atendendo à fonte de sua inspiração. Chamou-se Musaios.

Dele sabemos suficientemente pouco para não inseri-lo na confusão das lutas entre as escolas. Mas sua sentença mais respeitada, introduzida subrepticiamente na tradição, é o destilado de uma teoria; como se, por trás, houvesse um processo de otimização, de redução ao essencial. Até os dias de hoje, constitui a medida de uma teoria completa, como se se tivesse pressentido seu alcance - o de uma cosmologia como representação espaço-temporal completa do universo - capaz de a tudo abranger.

A única e singular frase de Musaios é: "Tudo provém da unidade e tudo voltará à unidade".

Mais não é preciso, e boa é a teoria que não necessita de mais que isso: a dos neoplatônicos, a dos cristãos e a dos modelos cosmológicos mais modernos, entre o ovo originário e a implosão que prepara o ovo seguinte. O mundo é sempre, apenas, o que existe no meio. Não vale a pena falar dele (BLUMENBERG 2003, p. 281-282, tradução nossa).

\section{Referências bibliográficas}

BLUMENBERG, Hans. Anthropologische Annährung an die Aktualität der Rhetorik.

In: Ästhetische und metaphorologische Schriften. Frankfurt am Main: Suhrkamp, 2001, p. 406-431.

Conceptos en historias. Madrid: Sintesis, 2003.

HEINRICH, Dieter. Werke im Werden: Über die Genesis philosophischer Einsichten. München: C. H. Beck, 2011.

KOSELLECK, Reinhardt. Über die Theoriebedürftigkeit der Geschichtswissenschaft. In: SCHIEDER, Theodor; GRÄUBIG, Kurt (Hrsg.) Theorieprobleme der 
Geschichtswissenschaft. Darmstadt: WissenschaftlicheBuchgesellschaft, 1977, p. 37-59.

MATA, Sérgio da. A fascinação weberiana: as origens da obra de Max Weber. Belo Horizonte: Fino Traço, 2013.

PATAI, Daphne; CORRAL, Will (eds.) Theory's Empire: an anthology of dissent. New York: Columbia University Press, 2005.

RAULFF, Ulrich; SCHLACK, Stephan. Zum Thema. Zeitschrift für Ideengeschichte, n. 4, p. 4, 2012.

RITTER, Joachim. Genie. In: RITTER, J. (Hrsg.) Historisches Wörterbuch der Philosophie, vol. 3. Basel: Schwab, 1974, cols. 279-309.

SCHÜTZ, Alfred. On multiple realities. In: Collected papers: the problem of social reality. The Hague: Martinus Nijhoff, 1973, p. 207-259.

SOUZA, Jessé. A modernização seletiva: uma reinterpretação do dilema brasileiro. Brasília: Ed. UnB, 2000. 